\title{
An oxidation and stable mounting technique for geothermally altered Upper Devonian palynomorphs from western Venezuela
}

\author{
CRAIG HARVEY \\ Centre for Palynology, University of Sheffield, Dainton Building, Brook Hill, Sheffield S3 7HF, UK.
}

\begin{abstract}
Upper Devonian sediments from western Venezuela have yielded palynomorphs that exhibit the palynomorph re-darkening and cracking phenomenon during post-oxidation mounting. A preparation technique has been developed, utilizing a diluted Schultze solution for prolonged periods, that appears not to affect substantially the structure of the palynomorphs, and thus prevents re-darkening. The use of PVA and Petropoxy 154 for mounting ensured the post-oxidative stability of the palynomorphs at room temperature. Conversely, the use of Elvacite 2044 as a mounting medium may cause cracking of the palynomorphs, related to shrinkage during solvent evaporation. J. Micropalaeontol. 20(2): 123-125, December 2001.
\end{abstract}

\section{INTRODUCTION}

The Upper Member of the Devonian Campo Chico Formation is exposed along the Venezuelan/Colombian border in the most northerly of the Devonian exposures within the Caño Colorado valley, Sierra de Perijá, western Venezuela. It comprises a series of grey/blue sandstones and shale interbeds with occasional green siltstones, containing the Upper Devonian progymnosperm Archaeopteris (C. Berry, pers. comm., 1997). Utilizing standard palynological preparation techniques, acid-insoluble organic residues containing excellently preserved, diverse and abundant spores, acritarchs and chitinozoans (Pl. 1, figs 1 and 2) were extracted from the siltstone and shale horizons. The palynomorphs are dark brown to opaque in transmitted light, indicating that the palynomorph assemblages are geothermally altered. Petrological analysis of two coal horizons associated with the Campo Chico Formation has revealed vitrinite reflectances of between 1.4 and $1.6 R_{\mathrm{v}}$, providing additional evidence of the regional geothermal alteration. During preparation of the Venezuelan material, at the post-oxidation mounting stage, the re-darkening phenomenon (Marshall, 1980) and cracking of the palynomorphs were encountered ( $\mathrm{Pl}$. 1, figs 3 and 4). Previously, a number of other workers have offered explanations and solutions to the re-darkening of Palaeozoic material (e.g. Playford \& Helby, 1968; Helby \& McElroy, 1969; Dolby, 1970; Deunff, 1977; Coquel \& Deunff, 1977; Marshall, 1980; Marshall \& Allen, 1982). Wood et al. (1996) suggest that the re-darkening may be a result of insufficient post-oxidation neutralization. This, however, is unlikely as it is possible to observe palynomorphs that degrade and dissolve in water during the evaporation process, and also in glycerine jelly during mounting (J. E. A. Marshall, pers. comm., 1999).

\section{OXIDATION}

During experimental oxidation of the Venezuelan material, increasingly stronger oxidizing agents were used. This involved the use of sodium hypochlorite solution $(5 \%)$, nitric acid $\left(\mathrm{HNO}_{3}\right)$ and fuming Schultze solution (sensu Marshall, 1980). Post-oxidation use of $2 \%$ potassium hydroxide $(\mathrm{KOH})$ to remove humic compounds was attempted, but resulted in the total disintegration of all acid-insoluble particles, including the palynomorphs.
The oxidizing agent found capable of clearing the spore assemblages was Schultze solution $\left(70 \% \mathrm{HNO}_{3}\right.$ saturated with $\mathrm{KClO}_{3}$ ), where assemblages cleared sufficiently after 18 hours. However, serious problems were encountered during the mounting stage, when the palynomorphs re-darkened and cracked (Pl. 1, figs 3 and 4). It was found that these problems were alleviated by using a mixture of $50 \mathrm{ml}$ Schultze solution added to $50 \mathrm{ml}$ of water containing the residue and left for 48 hours. Using this technique, which essentially trades speed for control, assemblages cleared sufficiently for light microscopy. The use of the modified Schultze solution appears to achieve a more uniform clearing of the whole assemblage and individual palynomorphs are less prone to fragment (Pl. 1, figs 5 and 6). In comparison with Schultze's (1855) original solution the total concentration of chlorine as chlorate $\left(\mathrm{ClO}_{3}\right)$ is lower and, therefore, the bleaching potential is significantly less. It is difficult, however, to test how the $\mathrm{ClO}_{3}$ ionizes in concentrated nitric acid compared to dilute nitric acid. Potentially, Schultze's procedure allowed more chlorine ions into the solution when compared to the modified solution used here. Marshall (1980, p. 317 , fig.1) reported the use of different concentrations of $50 \%$ nitric acid to fuming Schultze to clear spore assemblages from southeast Shetland and Fair Isle.

\section{MOUNTING}

Residues treated overnight with standard Schultze were mixed with Polyvinyl alcohol (PVA) and pipetted onto $22 \times 22 \mathrm{~mm}$ glass coverslips and left to dry on a warm plate $\left(60^{\circ} \mathrm{C}\right)$ for approximately 3 hours. Palynomorphs remained unaffected during this process. However, when the coverslips were mounted using Petropoxy 154 and cured for 30 minutes at $135^{\circ} \mathrm{C}$, the assemblages immediately reverted back to an opaque condition (Pl. 1, fig. 3). Similar observations were noted when these residues were mounted in Elvacite and, using this mounting medium, the palynomorphs also experienced a cracking effect (Pl. 1, fig. 4). Similar cracking was figured by Marshall (1980) when spores were freeze-dried and then mounted in Elvacite 2044. Furthermore, this phenomenon has also been observed when certain spore assemblages are dried at room temperature (J. E. A. Marshall, pers. comm., 1999). 

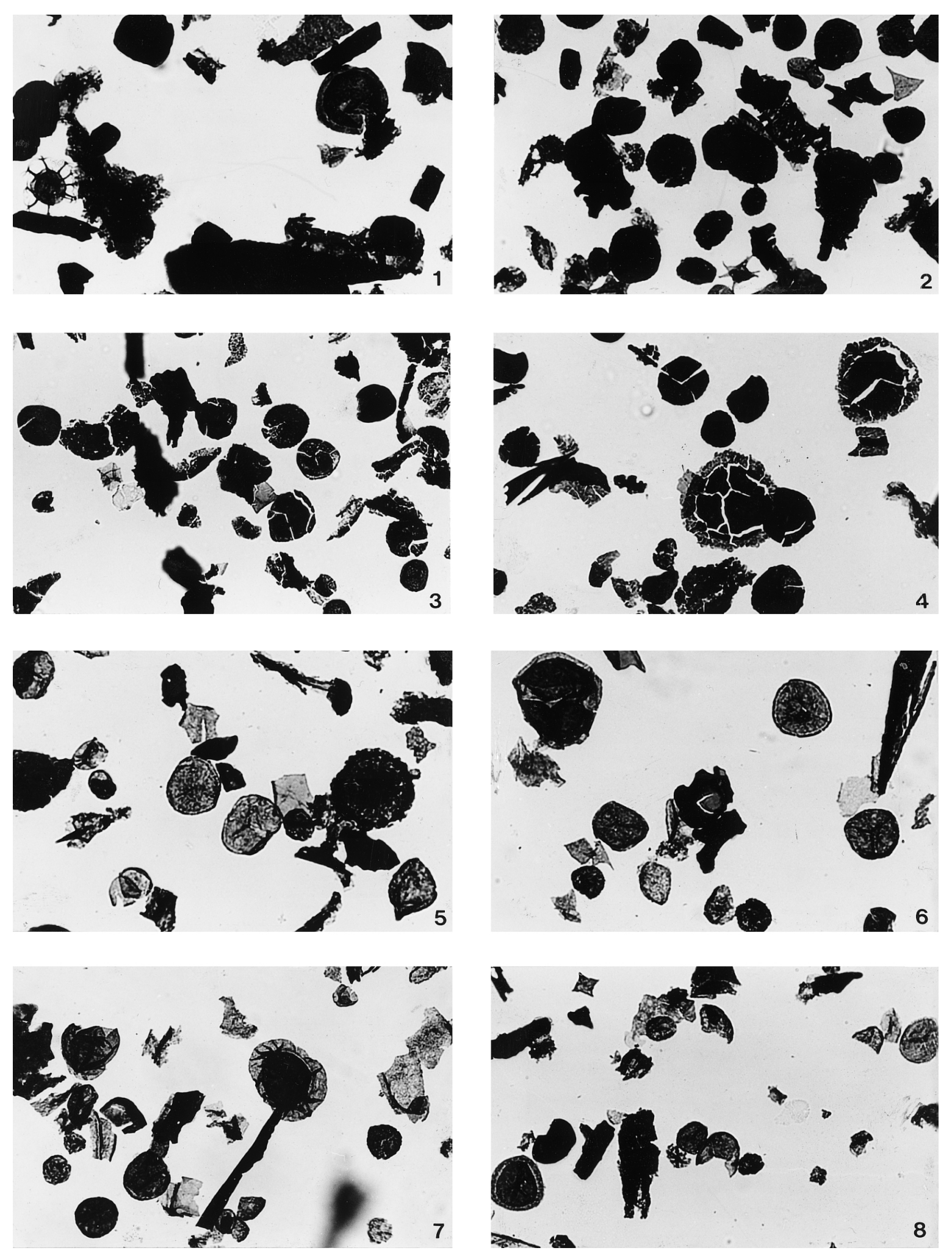
An oxidation technique for palynomorphs

Palynological residues treated with the diluted Schultze solution were dried in 2\% PVA and mounted in Petropoxy 154 at $135^{\circ} \mathrm{C}$ for 30 minutes. Palynomorphs remained light in colour and have not re-darkened or cracked, even after 18 months stored at room temperature (P1. 1, figs 5 and 6). This mounting technique, therefore, avoids the need to keep slides refrigerated and to fully examine them within weeks of preparation. A fraction of the same residue was also dried on the warm plate $\left(60^{\circ} \mathrm{C}\right)$ and mounted in Elvacite and, despite the assemblage remaining light in colour, all palynomorphs underwent the cracking phenomenon.

In view of the difficulties associated with mounting mediums, several other media were tested. The use of Cellosize $(<1 \%$ solution in water) as the adhesive medium with Petropoxy 154 produced comparable results as those provided by PVA (Pl. 1, fig. 7). Also, the use of water-based mountants, including glycerine jelly and Aquamount, did not produce the redarkening or cracking phenomenon (Pl. 1, fig. 8).

\section{CONCLUSIONS}

The re-darkening phenomenon was observed only in organic residues which underwent harsh oxidation (i.e. overnight Schultze solution) but not in those oxidized using the modified Schultze solution. As indicated by Marshall (1980), it seems probable that the re-darkening is related to high geothermal alteration (in this case 1.4-1.6 $R_{\mathrm{v}}$ ), requiring a high maceration level to oxidize the assemblages, accompanied by a subsequent structural decomposition of the spore exine. The use of a modified Schultze solution for prolonged periods appears not to have affected the structure of the palynomorphs sufficiently to allow the assemblages to re-darken. Subsequently, residues were stable during mounting procedures, even with the high temperatures involved. The desiccation of residues on the unmounted coverslips on a warm plate does not appear to promote either the re-darkening or cracking conditions. The use of Elvacite 2044 as a mounting medium has the potential to affect assemblages of high thermal maturity by causing cracking in the entire palynomorph assemblage. This is probably related to shrinkage of the Elvacite during mounting due to evaporation of the solvent.

\section{ACKNOWLEDGEMENTS}

The author thanks K. J. Dorning, J. E. A. Marshall (Southampton) and C. H. Wellman for comments on initial drafts of the paper. Palynological preparations were undertaken at the Centre for Palynology, University of Sheffield and the help of S. J. Ellin, H. B. M. Ahmed and B. L. H. Pigott is gratefully acknowledged.

\section{Manuscript received 5 March 1999 Manuscript accepted 12 January 2001}

\section{REFERENCES}

Coquel, R. \& Deunff, J. 1977. Sur a découverte de spores du passage Devonien Carbonifère (Strunien) dans le complex schisteux de la 'brèche du Dourduff' (région de Morlaix, Finistère) et sa signification. Compte rendus de l' Academie des sciences, (Paris), 284: 15-18.

Deunff, J. 1977. Sur une methode ccomplémentaire de traitement et d'eclaircissement du microplancton paléozoique carbonifié. Bulletin du Bureau de recherches geologiques et minieres, Sér 2, Sec. I, No 1: $51-54$.

Dolby, G. 1970. A Palynological investigation into the Devonian Carboniferous transition Measures in $S . W$. Britain and S. Eire. PhD thesis. University of Sheffield, England.

Helby, R. J. \& McElroy, C. T. 1969. Microfloras from the Devonian and Triassic Beacon group Antarctica. New Zealand Journal of Geology and Geophysics, 12: 376-382.

Marshall, J. E. A. 1980. A method for the successful oxidation and subsequent stabilisation of highly carbonised spore assemblages. Review of Palaeobotany and Palynology, 29: 313-319.

Marshall, J. E. A. \& Allen, K. C. 1982. Devonian miospore assemblages from the Fair Isle Shetland. Palaeontology, 25: 277-312.

Playford, G. \& Helby, R. J. 1968. Spores from the Carboniferous section in the Hunter Valley, N.S.W. Journal of the Geological Society of Australia, 15: 103-109.

Schultze, F. 1855. Uber das Vorkommon wohler haltener Cellulose in Braunkohle und Steinkohle Bericht uber die zur Bekanntmachung geeigneten Verhandlungen der Königlich Preussischen Akademie der Wissenschaften zu Berlin: 676-678.

Wood, G. D., Gabriel, A. M. \& Lawson, J. C. 1996. Palynological techniques - processing and microscopy. In Jansonius, J. \& McGregor, D. C. (Eds), Palynology: principles and applications, Volume 1 - Principles, 29-50. American Association of Stratigraphic Palynologists Foundation, Texas, USA.

Explanation of Plate 1.

Figs 1-8. Palynofacies assemblages, Upper Member of the Campo Chico Formation, western Venezuela: 1, a kerogen assemblage mounted in Petropoxy 154 ( $\times 100)$ (sample Va-114, slide BK, England Finder reference J39); 2, a kerogen assemblage mounted in Petropoxy 154 ( $\times 125)($ sample Va-104, slide 1K, England Finder reference U35); 3, an oxidized (Schultze solution) assemblage mounted in Petropoxy 154 $(\times 100)($ Sample Va-104, slide 1, England Finder reference R36); 4, an oxidized (Schultze solution) assemblage mounted in Petropoxy 154 ( $\times 125)($ Sample Va-114, slide 1, England Finder reference Q40/4); 5, an oxidized (dilute Schultze) assemblage mounted in Petropoxy 154 ( $\times 100)($ Sample Va-114, slide 1S, England Finder reference M38); 6, an oxidized (dilute Schultze) assmblage mounted in Petropoxy 154 assemblage $(\times 125)($ Sample Va-104, slide 1S, England Finder reference U45); 7, an oxidized (dilute Schultze) assemblage mounted in cellosize $(\times 100)$ (Sample Va-83, slide 2S, England Finder reference P30/3); 8, an oxidized (dilute Schultze) assemblage mounted in glycerine jelly assemblage $(\times 100)$ (Sample Va-83, slide 2S, England Finder reference U40/4). All slides are housed in the collections of the Centre for Palynology, University of Sheffield, England. 